\title{
Surgical treatment of velopharyngeal insufficiency
}

\author{
Seung Min Nam \\ Department of Plastic and \\ Reconstructive Surgery, Soonchunhyang \\ University Bucheon Hospital, \\ Soonchunhyang University College of \\ Medicine, Bucheon, Korea
}

\begin{abstract}
Velopharyngeal insufficiency (VPI) is a common complication after primary palatoplasty. Although the several surgical treatments of VPI have been introduced, there is no consensus guide to select the optimal surgical treatment for VPI patients. The selection of surgical treatment for VPI depends on a multimodal patient evaluation, such as perceptual speech evaluation, nasometery and nasoendoscopy. We can provide more adequate treatment for VPI through the deeper understanding of anatomy and physiology in VPI.
\end{abstract}

Keywords: Sphincter pharyngoplasty / Velopharyngeal insufficiency

\section{INTRODUCTION}

The primary goal of cleft palate repair is the achievement of optimal feeding and normal speech while minimally effect maxillary growth and development [1]. To achieve normal speech, the patients must have the ability to completely velopharyngeal port that separates the oro and nasopharynx. The absence of this ability, this disorder is referred to as velopharyngeal insufficiency (VPI), defined as an anatomical or structural defect result from inadequate closure of the velopharyngeal valve. Although the cleft palate operation is successful, $5 \%$ to $40 \%$ of cleft palate patients present abnormal speech resonance because of residual anatomical structural abnormalities [2].

Surgical management of VPI has been attempted since first reported by Passavant in 1865 [1]. He reported that the direct adhesion of the soft palate to the posterior pharyngeal wall. The pharyngeal flap was introduced by Sheonborn in 1875 and this flap was popularized in United States by Pagett in 1930 [3]. Several modification of pharyngeal flap has been focused on minimizing nasal emission and preventing airway obstruction $[4,5]$.

\section{Correspondence: Seung Min Nam}

Department of Plastic and Reconstructive Surgery, Soonchunhyang University Bucheon Hospital, Soonchunhyang University College of Medicine, 170 Jomaruro, Wonmi-gu, Bucheon 14584, Korea

E-mail: zodiac1003@naver.com

*This work was supported by the Soonchunhyang University Research Fund.

Received August 19, 2018 / Revised August 19, 2018 / Accepted September 19, 2018
Hynes [6] introduced sphincter pharyngoplasty in 1950. Since his first introduction, numerous modification have been made to sphincter pharyngoplasty and it is a useful surgical method for correcting VPI $[7,8]$. Orticochea modified lower flap inset and inclusion of inferior based pharyngeal flap in 1968 [9]. Jackson and Silverton [7] reported the combination a sphincter pharyngoplasty with a superior based pharyngeal flap. Riski et al. [8] reported the higher fixation of the myomucosal flap to posterior pharyngeal wall that was located the point of velar contact.

\section{PATIENT EVALUATION}

The most common cause of VPI in cleft palate patient is insufficient length of palate, inadequate levator veli muscle sling and cicatricial contracture of velum [10]. Other causes of VPI included submucosal cleft palate, neurogenic VPI that caused by the cranial nerve inadequately innervate the velopharyngeal mechanism and iatrogenic VPI caused by maxillary resection, uvulopalatopharyngoplasty or adenoidectomy [11-17].

\section{Speech evaluation}

It is very important that the patient with suspected VPI should be evaluated by speech pathologist before considering surgical procedure. Preoperative perceptual speech evaluation conducted by one of two speech pathologists, both of whom had greater 
than or equal to 10 years of experience in our clinic. We use the perceptual speech evaluation was performed using the universal parameters and rating system [18]. This system consisted of hypernasality, hyponasality, nasal emission, articulation errors, intelligibility and presence of compensatory articulation such as glottal stop, pharyngeal stop or pharyngeal fricatives. Hypernasality was graded on a numeric scale as follows: the normal is grade 0 , the mild hypernasality is grade 1 , the moderate hypernasality is grade 2, and the severe hypernasality is grade 3 [18]. Interrater and intrarater reliabilities were investigated using weight kappa statistics to assess observer variability in measuring hypernasality [19].

\section{Instrumental evaluation of the velopharyngeal function}

There are several diagnostic modalities to evaluate the dynamic function of velopharyngeal port and its closure pattern. The three basic closure patterns of velopharyngeal port are as follows: (1) coronal, the posterior movement of the velum is mainly contributed to close of velopharyngeal port, with minorly medial displacement of lateral pharyngeal wall; (2) sagittal, the medial displacement of lateral pharyngeal wall is mainly contributed to close of velopharyngeal port, with minorly posterior movement of the velum; (3) circular, the posterior movement of the velum and the pharyngeal wall contribute to close of velopharyngeal port.

Nasoendoscopy evaluation is a flexible endoscope inserted through the middle meatus and located the upper part of velopharyngeal port to provide visualizing the velopharyngeal mechanism while the patient phonates a sample speech. Nasoendoscopy provides the information of the size and location of velopharyngeal gap and relative contribution of the velum, lateral pharyngeal wall and posterior pharyngeal wall while velopharyngeal port is closing.

Recently, magnetic resonance imaging (MRI) is more popularly used in VPI evaluation. It can provide the information about the anatomy of velopharyngeal mechanism. The major advantage of MRI is noninvasive evaluation technique to avoid radiation hazard in VPI patients [20]. However, it cannot provide the precise images without motion related artifact while the patient phonates the sample speech $[20,21]$. It is expected that MRI will provide a more precise and better tolerated evaluation of the velopharyngeal mechanism through the further development of technology in the future.

Nasometery can provide the objective evaluation of the acoustic energy occurred form nasal cavity while the patients phonate the sample speech [22]. Nasometery consists of headset with two microphones located in the front of nose and mouth and two microphones are separated with metallic plate to iso- late acoustic energy from nasal and oral cavity. It represents the proportion of nasal/total acoustic energy emission as nasalance scores comparing with normal speech data [23]. Although nasometery provides the pure objective evaluation of acoustic energy, it can provide the most comprehensive speech evaluation when it combine with the perceptual speech evaluation by speech pathologist [24].

\section{OPERATIVE PROCEDURE}

\section{Furlow palatoplasty (double opposing Z-plasty)}

Furlow reported the double opposing Z-plasty technique for repairing cleft palate in 1986 [25]. This technique changed the abnormal inserted levator veli muscle into a more anatomic, posterior and transverse position and it can provide adequate the levator sling and sufficient length of velum $[25,26]$. The major advantage of this technique is that it can be applied in all VPI patients regardless of the primary palatoplasty technique. The most common drawback in double opposing Z-plasty is like to occur the inadequate palatal length or levator muscle function. The optimal function of levator muscle can be reconstructed by the removal scar tissue surrounding levator muscle.

\section{Overlapping intravelar veloplasty with oral Z-plasty}

This technique was reported by Woo et al. [27] in 2014 and it is detailly described as follows. Briefly, the levator veli palatine musculature is released and separated from surrounding muscular attachments and is continuedly dissected until its origin is encountered. The oral Z-plasty was performed and the levator are overlapped on each other, with both ends anchored to the body of the opposite muscle [27]. He argued that his technique is a safe and effective procedure for the management of VPI and the results of his technique can be achieved favorably velopharyngeal competence postoperatively comparing with Furlow palatoplasty [27].

\section{Pharyngeal flap}

There are many factors, that are contributed to poor outcomes and persistent VPI in spite of secondary palatoplasty, include poor lateral pharyngeal wall movement, abnormal muscular action and an obtuse basicranium. To overcome poor results, Shprintzen et al. [5] advocated the high and wide flap in spite of its technical difficulties because of limited visualization. However, if the width of flap is wide, the donor site is healed by secondary intension. A endotracheal tube is located in each port to prevent postoperative scar contracture between the lateral pharyngeal wall and the lateral aspect of the pharyngeal flap and is removed in 1 week after surgery. 
The most serious complication of pharyngeal flap is airway obstruction. Several articles have been reported that airway obstruction after pharyngeal flap conducted [28-31]. A prospective randomized study reported Dexamethasone $(0.25 \mathrm{mg} / \mathrm{kg})$, administered for three does over 24 hours, decreases the incidence of postoperative airway distress [32]. Moreover, if the patient have velocardiofacial syndrome, the medial displacement of internal carotid artery can be occurred [33-35]. This anatomical anomaly of velocardiofacial syndrome may disturb the width of proposed pharyngeal flap or can be provoked unpredicted significant intraoperative complications.

\section{Sphincter pharyngoplasty}

We performed sphincter pharyngoplasty as described by Orticochea [9] in 1968. We modified Orticochea sphincter pharyngoplasty that combined posterior pharyngeal wall augmentation using acellular dermal matrix. Briefly, under general anesthesia, the posterior wall of the pharynx was exposed with the aid of Dingman gag retraction. The exposure was increased by stitching a rubber catheter, passed through the nose, to the uvula and pulling it anteriorly into the nasopharynx [36]. An incision is made along the anterior mucosa of the posterior tonsillar pillar. The vertical fibers of the palatopharyngeal muscle are dissected bluntly from the transverse fibers of the superior pharyngeal constrictor [37]. The palatopharyngeal muscle has considerable substance and as much of it as possible should be elevated, avoiding any shredding of its fibers. The distal attachments of the palatopharyngeal myomucosal flap are divided. If there is good quality muscle in it, the flap immediately contracts.

A transverse incision is then made on the posterior pharyngeal wall through mucosa and muscle, connecting the upper limits of the two vertical defects created by the elevation of the palatopharyngeal muscle. This incision should coincide approximately with the level of the soft palate. The distal end of palatopharyngeal myomucosal flaps are sutured to each other, end to end, with absorbable sutures. The anterior edge of the palatopharyngeal myomucosal flap is sutured to the lower limb of the incision on the posterior pharynx. After we inserted acellular dermal matrix, the inferior edge of flap is sutured to the upper limb of incision, completing the formation of the sphincter.

When we perform sphincter pharyngoplasty, the highest inset point of palatopharyngeal myomucosal flap is the base of the adenoid gland, because the adenoid gland cannot provide secure fixation. If the patient have the low positioned adenoid gland, the inferior adenoidectomy should be performed to obtain the desired inset level, as the same level of velopharyngeal closure, of palatopharyngeal myomucosal flap. At least 6 weeks after inferior adenoidectomy, the posterior pharyngeal wall can provide the adequate healing to allow the secure fixation of myomucosal flap.

The sphincter pharyngoplasty has two advantages. First, it creates the dynamic structure to help the velopharyngeal closure. Second, if the patient persist hypernasality in spite of performing sphincter pharyngoplasty, the revision procedure, such as the reelevation and further overlap of the palatopharyngeal myomucosal flap, is simple procedure so, the persisted hypernasality easily can be resolved.

\section{Author's preferred algorithmic approach}

The VPI surgical management is selected based on the closure pattern and gap size of velopharyngeal port. If the patient have the sagittal closure pattern and small gap of VP port, the only overlapping intravelar veloplasty with oral Z-plasty sufficiently can be resolved VPI. If the patient have the sagittal closure pattern and intermediate or large gap of VP port, the superior based pharyngeal flap is recommended. After pharyngeal flap, this patient have the low incidence of airway obstruction because the good movement of lateral pharyngeal wall prevent airway complications. If the patient have the coronal closure pattern and small or intermediate gap of VP port, the sphincter pharyngoplasty is recommended. If the patient with the poor movement of lateral pharyngeal wall is treated by pharyngeal flap, the incidence of airway obstruction is increased. When the patient have the coronal closure pattern and large gap of VP port, it is very challenging case in VPI treatment. If the patient have these conditions, we recommend the combined overlapping intravelar veloplasty with oral Z-plasty and sphincter pharyngoplasty. When the patient have the circular closure pattern of VP port, we consider the gap size of VP port. If the patient have the small gap of VP port, the overlapping intravelar veloplasty was recommended and, if the intermediate or large gap, the pharyngeal flap was recommended (Table 1).

Table 1. Author's preferred algorithmic approach

\begin{tabular}{|c|c|c|}
\hline VP port closure pattern & VP gap size & Preferred surgical treatment \\
\hline \multirow[t]{2}{*}{ Sagittal } & $\begin{array}{l}\text { Small and } \\
\text { intermediate }\end{array}$ & Overlapping IVV with oral Z-plasty \\
\hline & Large & Superior based pharyngeal flap \\
\hline \multirow[t]{2}{*}{ Coronal } & $\begin{array}{l}\text { Small and } \\
\text { intermediate }\end{array}$ & Sphincter pharyngoplasty \\
\hline & Large & $\begin{array}{l}\text { Combined overlapping IVV with oral } \\
\text { Z-plasty and sphincter pharyngoplasty }\end{array}$ \\
\hline \multirow[t]{2}{*}{ Circular } & Small & Overlapping IVV with oral Z-plasty \\
\hline & $\begin{array}{l}\text { Intermediate or } \\
\text { large }\end{array}$ & Superior based pharyngeal flap \\
\hline
\end{tabular}

VP, velopharyngeal; IVV, intravelar veloplasty. 
We prefer the sphincter pharyngoplasty to the pharyngeal flap except in cases of velocardiofacial syndrome because the sphincter pharyngoplasty is easily able to revise when the patient have the persistent hypernasality.

\section{CONCLUSIONS}

VPI is a common complication after primary palatoplasty. Although the several surgical treatment of VPI have been introduced, there is no consensus guide to select the optimal surgical treatment for VPI patients. The selection of surgical treatment for VPI depends on a multimodal patient evaluation, such as perceptual speech evaluation, nasometery and nasoendoscopy. We can provide more adequate treatment for VPI through the deeper understanding of anatomy and physiology in VPI.

\section{CONFLICT OF INTEREST}

No potential conflict of interest relevant to this article was reported.

\section{REFERENCES}

1. Gart MS, Gosain AK. Surgical management of velopharyngeal insufficiency. Clin Plast Surg 2014;41:253-70.

2. Ahmed M. Cleft lip and palate care in the United Kingdom: the Clinical Standards Advisory Group (CSAG) study. Cleft Palate Craniofac J 2002;39:656.

3. Padgett EC. The repair of cleft palates after unsuccessful operations with special reference to cases with an extensive loss of palatal tissue. Int J Orthodontia Oral Surg Radiogr 1930;16: 1299-316.

4. Hogan VM. A clarification of the surgical goals in cleft palate speech and the introduction of the lateral port control (l.p.c.) pharyngeal flap. Cleft Palate J 1973;10:331-45.

5. Shprintzen RJ, Lewin ML, Croft CB, Daniller AI, Argamaso RV, Ship AG, et al. A comprehensive study of pharyngeal flap surgery: tailor made flaps. Cleft Palate J 1979;16:46-55.

6. Hynes W. Pharyngoplasty by muscle transplantation. Br J Plast Surg 1950;3:128-35.

7. Jackson IT, Silverton JS. The sphincter pharyngoplasty as a secondary procedure in cleft palates. Plast Reconstr Surg 1977;59: 518-24.

8. Riski JE, Serafin D, Riefkohl R, Georgiade GS, Georgiade NG. A rationale for modifying the site of insertion of the orticochea pharyngoplasty. Plast Reconstr Surg 1984;73:882-94.

9. Orticochea M. Construction of a dynamic muscle sphincter in cleft palates. Plast Reconstr Surg 1968;41:323-7.
10. Chen PK, Wu JT, Chen YR, Noordhoff MS. Correction of secondary velopharyngeal insufficiency in cleft palate patients with the Furlow palatoplasty. Plast Reconstr Surg 1994;94:93341.

11. Lewin ML, Croft CB, Shprintzen RJ. Velopharyngeal insufficiency due to hypoplasia of the musculus uvulae and occult submucous cleft palate. Plast Reconstr Surg 1980;65:585-91.

12. Yoshida H, Michi K, Ohsawa T. Prosthetic treatment for speech disorders due to surgically acquired maxillary defects. J Oral Rehabil 1990;17:565-71.

13. Finkelstein Y, Shifman A, Nachmani A, Ophir D. Prosthetic management of velopharyngeal insufficiency induced by uvulopalatopharyngoplasty. Otolaryngol Head Neck Surg 1995; 113:611-6.

14. Conley SF, Gosain AK, Marks SM, Larson DL. Identification and assessment of velopharyngeal inadequacy. Am J Otolaryngol 1997;18:38-46.

15. Shifman A, Finkelstein Y, Nachmani A, Ophir D. Speech-aid prostheses for neurogenic velopharyngeal incompetence. J Prosthet Dent 2000;83:99-106.

16. Hubbard BA, Rice GB, Muzaffar AR. Adenoid involvement in velopharyngeal closure in children with cleft palate. Can J Plast Surg 2010;18:135-8.

17. Rilo B, Fernandez-Formoso N, da Silva L, Pinho JC. A simplified palatal lift prosthesis for neurogenic velopharyngeal incompetence. J Prosthodont 2013;22:506-8.

18. Henningsson G, Kuehn DP, Sell D, Sweeney T, Trost-Cardamone JE, Whitehill TL, et al. Universal parameters for reporting speech outcomes in individuals with cleft palate. Cleft Palate Craniofac J 2008;45:1-17.

19. Landis JR, Koch GG. The measurement of observer agreement for categorical data. Biometrics 1977;33:159-74.

20. Kao DS, Soltysik DA, Hyde JS, Gosain AK. Magnetic resonance imaging as an aid in the dynamic assessment of the velopharyngeal mechanism in children. Plast Reconstr Surg 2008; 122:572-7.

21. Silver AL, Nimkin K, Ashland JE, Ghosh SS, van der Kouwe AJ, Brigger MT, et al. Cine magnetic resonance imaging with simultaneous audio to evaluate pediatric velopharyngeal insufficiency. Arch Otolaryngol Head Neck Surg 2011;137:258-63.

22. Fletcher SG, Bishop ME. Measurement of nasality with tonar. Cleft Palate J 1970;7:610-21.

23. Fletcher SG. "Nasalance" vs. listner judgements of nasality. Cleft Palate J 1976;13:31-44.

24. Karnell MP. Instrumental assessment of velopharyngeal closure for speech. Semin Speech Lang 2011;32:168-78.

25. Furlow LT Jr. Cleft palate repair by double opposing Z-plasty. Plast Reconstr Surg 1986;78:724-38. 
26. Furlow LT Jr. Flaps for cleft lip and palate surgery. Clin Plast Surg 1990;17:633-44.

27. Woo AS, Skolnick GB, Sachanandani NS, Grames LM. Evaluation of two palate repair techniques for the surgical management of velopharyngeal insufficiency. Plast Reconstr Surg 2014;134:588e-596e.

28. Jackson P, Whitaker LA, Randall P. Airway hazards associated with pharyngeal flaps in patients who have the Pierre Robin syndrome. Plast Reconstr Surg 1976;58:184-6.

29. Kravath RE, Pollak CP, Borowiecki B, Weitzman ED. Obstructive sleep apnea and death associated with surgical correction of velopharyngeal incompetence. J Pediatr 1980;96:645-8.

30. Thurston JB, Larson DL, Shanks JC, Bennett JE, Parsons RW. Nasal obstruction as a complication of pharyngeal flap surgery. Cleft Palate J 1980;17:148-54.

31. Valnicek SM, Zuker RM, Halpern LM, Roy WL. Perioperative complications of superior pharyngeal flap surgery in children. Plast Reconstr Surg 1994;93:954-8.
32. Woo AS. Evidence-based medicine: cleft palate. Plast Reconstr Surg 2017;139:191e-203e.

33. MacKenzie-Stepner K, Witzel MA, Stringer DA, Lindsay WK, Munro IR, Hughes H. Abnormal carotid arteries in the velocardiofacial syndrome: a report of three cases. Plast Reconstr Surg 1987;80:347-51.

34. Lai JP, Lo LJ, Wong HF, Wang SR, Yun C. Vascular abnormalities in the head and neck area in velocardiofacial syndrome. Chang Gung Med J 2004;27:586-93.

35. Even-Or E, Wohlgelernter J, Gross M. Medial displacement of the internal carotid arteries in velocardiofacial syndrome. Isr Med Assoc J 2005;7:749-50.

36. James NK, Twist M, Turner MM, Milward TM. An audit of velopharyngeal incompetence treated by the orticochea pharyngoplasty. Br J Plast Surg 1996;49:197-201.

37. Stratoudakis AC, Bambace C. Sphincter pharyngoplasty for correction of velopharyngeal incompetence. Ann Plast Surg 1984;12:243-8. 